\title{
Clinical Implications of Transbronchial Biopsy for Surgically-resected Non-small Cell Lung Cancer
}

\author{
MOTOAKI YASUKAWA, NORIYOSHI SAWABATA, TAKESHI KAWAGUCHI, \\ NORIKAZU KAWAI and SHIGEKI TANIGUCHI \\ Department of Thoracic and Cardiovascular Surgery, \\ Nara Medical University School of Medicine, Nara, Japan
}

\begin{abstract}
Background/Aim: Lung biopsies might cause metastasis and/or dissemination. The aim of this study was to review our institutional experience and analyze the outcomes of resection for non-small cell lung cancer (NSCLC), in patients who had received preoperative transbronchial biopsy using fiberoptic bronchoscopy with fluoroscopic imaging (BFS). Patients and Methods: The medical records of consecutive patients between 2010 and 2015 were retrospectively reviewed. Patients were divided into two groups (BFS and Non-BFS). Overall survival (OS) curves and recurrence-free survival (RFS) curves were plotted using the Kaplan-Meier method. Cox regression analyses were used to evaluate the hazard ratio (HR) with the endpoint OS or RFS. Results: We studied the medical records of 531 patients. The 5-year OS rate was $91.8 \%$ and $79.8 \%$, in the BFS group and in the Non-BFS group, respectively $(p<0.001)$. BFS was an independent factor associated with RFS HR=2.164 (95\%CI=1.399-2.346). Conclusion: Preoperative BFS is a prognostic factor in patients receiving surgery for NSCLC.
\end{abstract}

Transbronchial biopsy (TBB) procedure using fiberoptic bronchoscopy with fluoroscopic imaging (BFS) is one of the standard diagnostic modalities for lung cancer. TBB occasionally causes complications owing to the need to access the bronchi and/or alveoli, where the cancer lesions are present. Though the pulmonary nodule is not torn off by forceps during the procedure, the cancer lesion may be disturbed, causing tumor cells to disseminate.

This article is freely accessible online.

Correspondence to: Motoaki Yasukawa, Department of Thoracic and Cardiovascular Surgery, Nara Medical University School of Medicine, Kashihara, Nara 634-8522, Japan. Tel: +81 744223051, Fax: +81 744248040, e-mail: myasukawa@naramed-u.ac.jp

Key Words: Non-small cell lung cancer, lung biopsy, prognosis.
The TBB procedure was reported in the early 2000s to be an indicator of poor prognosis in patients with resectable non-small cell lung cancer (NSCLC) (1). However, because of the changing demographics of patients with lung cancer, increasing the frequency of early-stage NSCLC (2), we believe that the prognosis for NSCLC patients, after preoperative TBB using BFS, is an important clinical question, and should be reconsidered.

The concept that biopsies might cause metastasis and/or dissemination of tumor cells has been known since the late 1970 s and is referred to as needle tract seeding (3). This has been shown both in ex vivo resected lung, and through tumor cell dislodgement by TBB resulting in circulating tumor cells (4). It should, also, be noted that inflammation has been suggested to play a key role in lung carcinogenesis (5) and that both chronic inflammation and acute inflammation is associated with tumorigenesis $(6,7)$.

We investigated the clinical implications of TBB before surgery in patients with lung cancer by reviewing the clinical records of patients who underwent resection for NSCLC with and without preoperative TBB using BFS.

\section{Patients and Methods}

Among 739 patients who underwent resection of NSCLC at Nara Medical University Hospital between January 2010 and December 2015, 531 NSCLC patients who underwent complete resection (lobectomy or more) were selected and their medical records reviewed. The clinical $\mathrm{T}$ descriptor was reclassified based on the eighth edition TNM staging (8). The exclusion criteria for entry into the study were the presence of other concomitant malignant diseases and determination of NSCLC by intraoperative needle lung biopsy (INB) or preoperative percutaneous needle biopsy such as computed tomography-guided lung biopsy (CTGLB). The remaining cases were divided into two groups: the group of patients who underwent TBB using BFS (Group BFS) and the group of patients who did not undergo BFS before surgery (Group Non-BFS).

Group BFS patients were divided into further two groups: Group TBB-Successful (Group Successful) included patients who were diagnosed with NSCLC following histopathological analysis of preoperative TBB and Group BFS-Unsuccessful (Group 
Table I. A patient clinico-pathological background.

\begin{tabular}{|c|c|c|c|}
\hline & BFS $(n=236)$ & Non-BFS $(n=295)$ & $p$-Value \\
\hline Age $<70 />70$ & $120 / 116$ & $145 / 150$ & 0.727 \\
\hline \multicolumn{4}{|l|}{ Gender } \\
\hline Male/Female & $160 / 76$ & $174 / 121$ & $0.038 *$ \\
\hline \multicolumn{4}{|l|}{ CT findings } \\
\hline Pure GGN/Others & $11 / 225$ & $74 / 221$ & $<0.001^{*}$ \\
\hline \multicolumn{4}{|l|}{ Location } \\
\hline Peripherial/Others & $173 / 63$ & $235 / 60$ & 0.098 \\
\hline \multicolumn{4}{|l|}{ c-Stage } \\
\hline $\mathrm{Tmin} / \mathrm{T} 1 \mathrm{a} / \mathrm{T} 1 \mathrm{~b} / \mathrm{T} 1 \mathrm{c} / \mathrm{T} 2 \mathrm{a} / \mathrm{T} 2 \mathrm{~b} / \mathrm{T} 3$ or more & $0 / 1 / 28 / 81 / 78 / 25 / 23$ & $6 / 23 / 128 / 84 / 35 / 14 / 5$ & 0.098 \\
\hline \multicolumn{4}{|l|}{ p-Stage } \\
\hline $\mathrm{Tmin} / \mathrm{T} 1 \mathrm{a} / \mathrm{T} 1 \mathrm{~b} / \mathrm{T} 1 \mathrm{c} / \mathrm{T} 2 \mathrm{a} / \mathrm{T} 2 \mathrm{~b} / \mathrm{T} 3$ or more & $0 / 6 / 26 / 57 / 82 / 33 / 32$ & $13 / 26 / 115 / 66 / 50 / 9 / 16$ & 0.098 \\
\hline Invasive size of the tumor $(\mathrm{cm})$ & 3.38 & 2.20 & \\
\hline$<3 />3$ & $115 / 121$ & $248 / 47$ & $<0.001^{*}$ \\
\hline $\mathrm{p}-\mathrm{N} 0 / \mathrm{N} 1 / \mathrm{N} 2$ or more & $170 / 41 / 25$ & $266 / 11 / 18$ & $<0.001^{*}$ \\
\hline \multicolumn{3}{|l|}{ Histology } & $<0.001^{*}$ \\
\hline Ad & 147 & 236 & \\
\hline $\mathrm{Sq}$ & 55 & 43 & \\
\hline Others & 34 & 16 & \\
\hline $\mathrm{Pl}+/-$ & $83 / 153$ & $48 / 247$ & $<0.001^{*}$ \\
\hline Ly +/- & $148 / 88$ & $95 / 200$ & $<0.001^{*}$ \\
\hline $\mathrm{V}+1-$ & $144 / 92$ & $80 / 215$ & $<0.001 *$ \\
\hline \multicolumn{4}{|l|}{ Preoperative CEA } \\
\hline$<5 />5 \mathrm{ng} / \mathrm{mL}$ & $150 / 86$ & $219 / 76$ & $0.010^{*}$ \\
\hline \multicolumn{4}{|l|}{ Period of days from point out to operation } \\
\hline$<90 />90$ & $147 / 90$ & $117 / 178$ & $<0.001 *$ \\
\hline Recurrence & 90 & 38 & $<0.001^{*}$ \\
\hline
\end{tabular}

BFS: Fiberoptic bronchoscopy with fluoroscopic imaging; CT: computed tomography; GGN: ground glass nodule; Ad: adenocarcinoma; Sq: squamous cell carcinoma; Pl: pleural invasion; Ly: lymphatic invasion; V: vascular invasion; CEA: carcinoembryonic antigen.

Unsuccessful) included patients who were not diagnosed with NSCLC following histopathological analysis of preoperative TBB. Instead, NSCLC in the Group Unsuccessful patients was diagnosed by the intraoperative partial resection of the lung using a stapling device. If partial resection was not possible, lobectomy or more (bilobectomy or pneumonectomy) was performed. Postoperative pathological analysis revealed NSCLC in all cases.

We used the video-assisted thoracoscopic surgery (VATS) technique to resect the lung cancers. This involved three incisions; a camera port was inserted in the anterior axillary line through the seventh or eighth intercostal space, a second $1 \mathrm{~cm}$ incision was made in the anterior axillary line through the fourth or fifth intercostal space, and a 4 to $5 \mathrm{~cm}$ working port was placed in the fourth or fifth intercostal space axillar.

Follow-up examinations were symptom-oriented, but all patients received medical checkups and chest X-rays at least twice a year and whole-body computed tomography (CT) scans were performed at least once a year. The observation period was terminated on October 31, 2017.

Either the chi squared test or Fisher's exact test was used, as appropriate, to analyze any correlation between the two groups. Overall survival curves and recurrence-free survival curves were plotted using the Kaplan-Meier method, and the statistical significance of differences between groups was determined by the log-rank test. Univariate and multivariate Cox regression analyses were used to evaluate the hazard ratio (HR) with the endpoint of overall survival (period from the day of operation to the day of death) or recurrence-free survival. All $p$-values were two-sided, and $p$-values of 0.05 were considered to indicate a statistically significant difference. All analyses were conducted using EZR on R commander version 1.33 (Saitama, JAPAN) (9).

The Ethics Review Board of our institute waived the requirement to obtain written informed consent from patients and approved the study protocol, because individual patients were not identified in this retrospective study.

\section{Results}

Two hundred thirty-six patients in the BFS group and 295 patients in the Non-BFS group were included in this study. The median follow-up period was 47 months (range $=1-91$ months). Table I shows the clinicopathological characteristics of the patients in both groups. There were statistically significant differences in the size of the tumor, statuses of lymph node metastasis, pleural invasion, and lymph-vascular involvement, which were more frequently observed in patients in the BFS group than in the Non-BFS group (Fisher's exact test).

During the observation period, NSCLC recurrence was identified in 90 patients in the BFS group and 38 patients in 


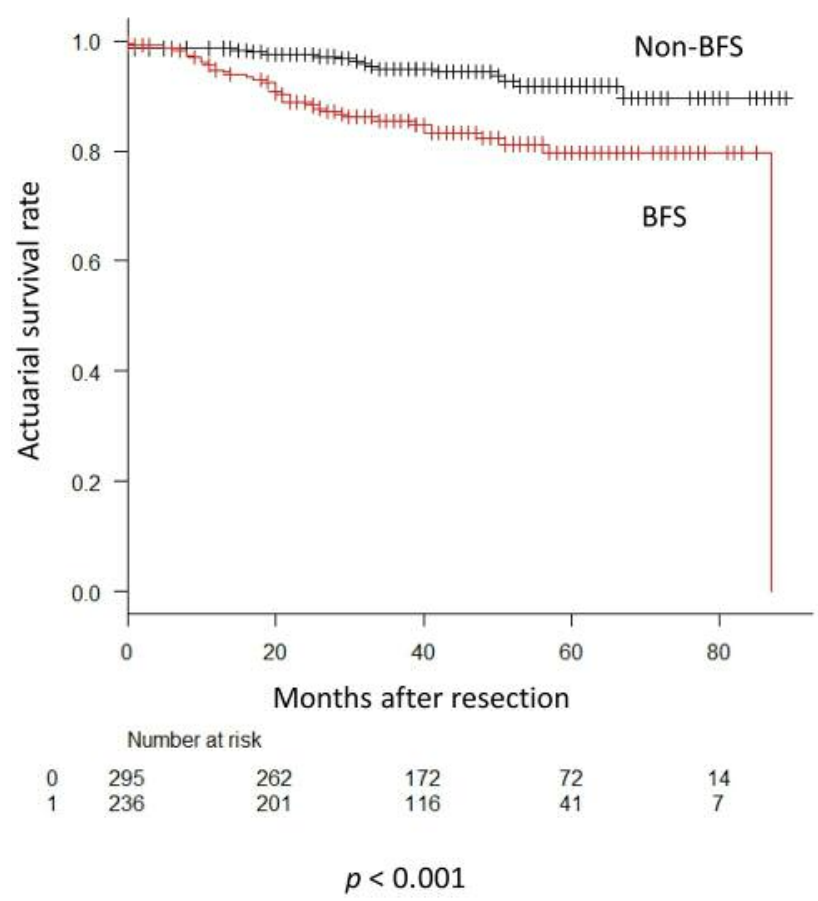

Figure 1. Overall survival curve for all patients according to receipt of BFS procedure. The 5-year overall survival rate was $91.8 \%$ in the BFS group and $79.8 \%$ in the Non-BFS group. The difference between the groups is significant $(p<0.001)$.

the Non-BFS group. The first recurrence sites were lymph node in 24 cases, brain in 21 cases, lung in 18 cases, dissemination in 11 cases, bone in 8 cases, liver in 4 cases, lymphangitis in 2 cases, and adrenal gland in 2 cases in the BFS group and lymph node in 16 cases, dissemination in 7 cases, lung in 7 cases, brain in 3 cases, bone in 3 cases, liver in 1 case, and lymphangitis in 1 case in the Non-BFS group. Thirty-eight patients in the BFS group and 18 patients in the Non-BFS group died during the observation period.

The 5-year overall survival rate was $91.8 \%(95 \% \mathrm{CI}=86.8$ $95.0 \%)$ and $79.8 \%(95 \% \mathrm{CI}=72.4-85.3 \%)$, in the BFS group and the Non-BFS group, respectively $(p<0.001)$ (Figure 1$)$. The 5-year recurrence-free survival rate was $82.3 \%$ $(95 \% \mathrm{CI}=75.7-87.3 \%)$ and $52.4 \%(95 \% \mathrm{CI}=43.5-60.5 \%)$, in the BFS group and the Non-BFS group, respectively $(p<0.001)$ (Figure 2).

In the analysis of relative risk with the endpoint of overall survival, the tumor infiltration size in CT, pathological tumor infiltration diameter, ground glass nodule (GGN), BFS, histological type, pleural invasion (pl) factor, vascular invasion (v) factor, lymphatic invasion (ly) factor, $\mathrm{pN}$ stage, preoperative carcinoembryonic antigen (CEA), and the period from tumor discovery to operation were indicators of survival, but in multivariate analysis, $\mathrm{v}$ factor was an independent survival predictor (Tables II and III). In the

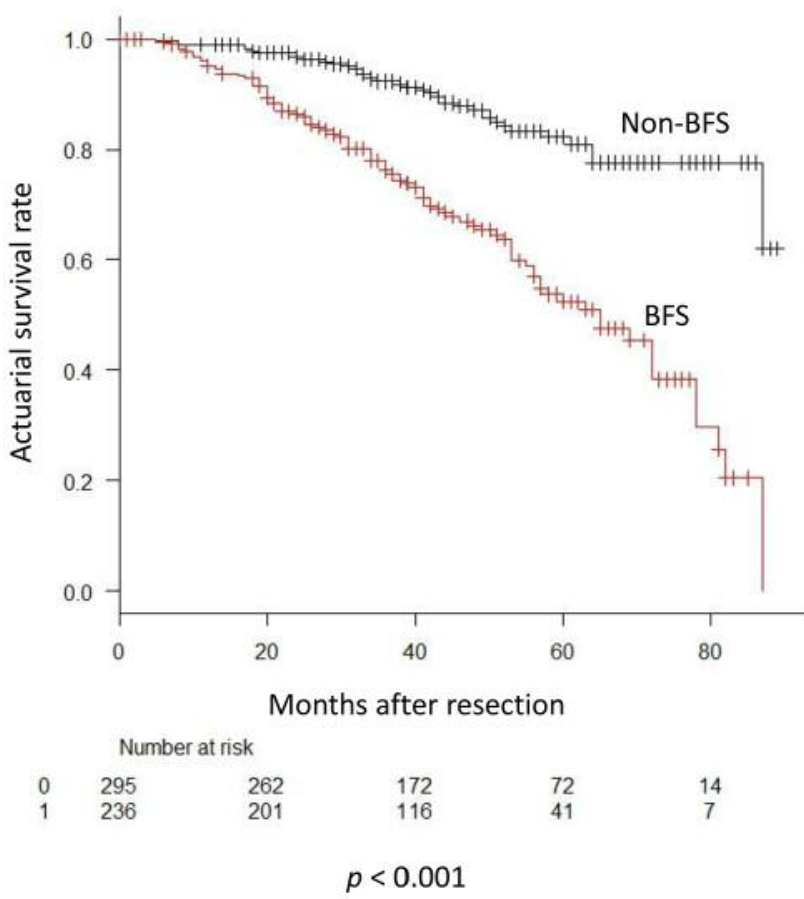

Figure 2. Recurrence-free survival curve for all patients according to receipt of BFS procedure. The 5-year recurrence-free survival rate was $82.3 \%$ in the BFS group and $52.4 \%$ in the Non-BFS group. The difference between the groups is significant $(p<0.001)$.

analysis of relative risk with the endpoint of cancer recurrence, the same measures were indicators of recurrence as for survival, whereas in multivariate analysis, age, BFS, $\mathrm{pN}$ stage, and $\mathrm{v}$ factor were independent recurrence predictors (Tables IV and V).

We carried out an extracted analysis depending on whether TBB was successful or not. There were 154 patients in the Successful group and 82 patients in the Unsuccessful group. Table VI shows the clinicopathological characteristics of the patients in both groups. There were no significant differences in the patient characteristics between the two groups except age and cT factor (Fisher's exact test).

During the observation period, NSCLC recurrence was identified in 62 patients in the Successful group and 28 patients in the Unsuccessful group. The first recurrence sites were lymph node in 18 cases, brain in 14 cases, lung in 11 cases, dissemination in 8 cases, bone in 6 cases, liver in 2 cases, lymphangitis in 2 cases, and adrenal gland in 1 case in the Successful group and lung in 7 cases, brain in 7 cases, lymph node in 6 cases, dissemination in 3 cases, bone in 2 cases, liver in 2 cases, and adrenal gland in 1 case in the Unsuccessful group. Twenty-three patients in the Successful group and 15 patients in the Unsuccessful group died during the observation period. The 5-year overall survival rate was $78.0 \%$ $(95 \% \mathrm{CI}=65.6-86.3 \%)$ and $80.2 \%(95 \% \mathrm{CI}=69.8-87.3 \%)$, in the 
Table II. Univariate analysis of factors influencing survival of all patients after complete resection of primary lung cancer.

\begin{tabular}{lccc}
\hline & Hazard ratio & $95 \% \mathrm{CI}$ & $p$-Value \\
\hline $\begin{array}{l}\text { Age }>70 \\
\text { Gender }\end{array}$ & 1.659 & $0.970-2.840$ & 0.065 \\
$\quad$ Male/Female & 2.401 & $1.268-4.548$ & $0.007^{*}$ \\
BFS & 2.958 & $1.648-5.196$ & $<0.001^{*}$ \\
$\begin{array}{l}\text { Period of days from point } \\
\text { out to operation }>90\end{array}$ & & & \\
Location & 0.463 & $0.266-0.806$ & $0.006^{*}$ \\
$\quad$ & & & \\
$\quad$ Peripherial & 1.455 & $0.734-2.884$ & 0.283 \\
Histology & & & \\
$\quad$ Sq/Non-Sq & 2.022 & $1.132-3.611$ & $0.017 *$ \\
$\quad$ Ad/Non-Ad & 0.365 & $0.216-0.617$ & $<0.001^{*}$ \\
Invasive size of the tumor $>3 \mathrm{~cm}$ & 3.182 & $1.876-5.399$ & $<0.001^{*}$ \\
p-N0/N1/N2 or more & 1.934 & $1.391-2.688$ & $<0.001^{*}$ \\
$\quad$ Pl + & 2.990 & $1.767-5.061$ & $<0.001^{*}$ \\
$\quad$ V + & 6.669 & $3.447-12.900$ & $<0.001^{*}$ \\
$\quad$ Ly + & 4.752 & $2.509-9.000$ & $<0.001^{*}$ \\
Preoperative CEA $>5 \mathrm{ng} / \mathrm{ml}$ & 2.284 & $1.351-3.863$ & $<0.002^{*}$ \\
\hline
\end{tabular}

CI: Confidence interval; BFS: fiberoptic bronchoscopy with fluoroscopic imaging; Sq: squamous cell carcinoma; Ad: adenocarcinoma; Pl: pleural invasion; V: vascular invasion; Ly: lymphatic invasion; CEA: carcinoembryonic antigen.

Successful group and the Unsuccessful group, respectively $(p=0.477)$ (Figure 3). The 5-year recurrence-free survival rate was $63.9 \%(95 \% \mathrm{CI}=50.3-74.7 \%)$ and $45.2 \%(95 \% \mathrm{CI}=33.7-$ $56.0 \%)$, in the Successful group and the Unsuccessful group, respectively $(p=0.282)$ (Figure 4$)$.

In the analysis of relative risk among Group BFS patients with the endpoint of survival, the tumor infiltration size in $\mathrm{CT}$, pathological tumor infiltration diameter, histological type, $\mathrm{pl}$ factor, $\mathrm{v}$ factor, ly factor, $\mathrm{pN}$ stage, preoperative $\mathrm{CEA}$, and the period from tumor discovery to operation were indicators of survival, but in multivariate analysis, $\mathrm{v}$ factor was the only independent survival predictor (Tables VII and VIII). In the analysis of relative risk among Group BFS patients with the endpoint of cancer recurrence, the same measures were indicators of recurrence as for survival, but in multivariate analysis, age, $\mathrm{pN}$ stage, $\mathrm{v}$ factor were independent recurrence predictors (Tables IX and X).

\section{Discussion}

In this study, the recurrence-free survival of the BFS group was significantly worse than that of the Non-BFS group and BFS was shown to be one of the independent predictive factors of recurrence in NSCLC patients.

BFS has been chosen for diagnosing primary lung cancer and TBB using BFS is one of the most important examinations to determine the pathologic diagnosis of an
Table III. Multivariate analysis of factors influencing survival of all patients after complete resection of primary lung cancer.

\begin{tabular}{|c|c|c|c|}
\hline & Hazard ratio & $95 \% \mathrm{CI}$ & $p$-Value \\
\hline Age $>70$ & 1.555 & $0.895-2.700$ & 0.117 \\
\hline \multicolumn{4}{|l|}{ Gender } \\
\hline Male/Female & 1.635 & $0.813-3.289$ & 0.168 \\
\hline BFS & 1.460 & $0.786-2.713$ & 0.231 \\
\hline Period of days from point & 0.810 & $0.454-1.445$ & 0.475 \\
\hline \multicolumn{4}{|l|}{ Location } \\
\hline Peripherial & 1.986 & $0.965-4.089$ & 0.063 \\
\hline \multicolumn{4}{|l|}{ Histology } \\
\hline Sq/Non-Sq & 0.818 & $0.370-1.812$ & 0.621 \\
\hline Ad/Non-Ad & 0.664 & $0.313-1.407$ & 0.285 \\
\hline Invasive size of the tumor $>3 \mathrm{~cm}$ & 1.325 & $0.726-2.418$ & 0.359 \\
\hline $\mathrm{p}-\mathrm{N} 0 / \mathrm{N} 1 / \mathrm{N} 2$ or more & 1.437 & $0.975-2.119$ & 0.067 \\
\hline $\mathrm{Pl}+$ & 1.117 & $0.620-2.013$ & 0.712 \\
\hline $\mathrm{V}+$ & 2.977 & $1.258-7.044$ & $0.013 *$ \\
\hline Ly + & 1.061 & $0.465-2.421$ & 0.889 \\
\hline Preoperative CEA $>5 \mathrm{ng} / \mathrm{ml}$ & 1.322 & $0.757-2.309$ & 0.327 \\
\hline
\end{tabular}

CI: Confidence interval; BFS: fiberoptic bronchoscopy with fluoroscopic imaging; Sq: squamous cell carcinoma; Ad: adenocarcinoma; Pl: pleural invasion; V: vascular Invasion; Ly: lymphatic invasion; CEA: carcinoembryonic antigen.

indeterminate pulmonary nodule, suspected to be lung cancer. Nakajima et al. (1) reported in 2005 that preoperative TBB procedure might worsen the prognosis of patients with resectable NSCLC. They described how neoplastic tissue was bluntly torn or brushed from the main tumor during TBB causing tumor cells to seed and/or disseminate vascular and lymphatic structures of the bronchi, alveoli, and pleura. The concept is similar to needle biopsy seeding. Despite a report describing the rarity of tumor seeding during needle biopsy procedures (10), needle tract seeding is one of the risks of needle biopsy, particularly in breast cancer and prostate cancer (3).

In this study, we carried out an extracted analysis according to whether TBB was successful or not. We hypothesized that the Successful group would have disseminated and/or seeded tumor cells, due to disturbance of the tumor, whereas this would not be the case for the Unsuccessful group. Our study showed no significant differences between the Successful group and Unsuccessful groups in the prognosis or recurrence after surgical resection. In brief, BFS was an independent indicator of recurrence, but successful diagnosis by TBB, which is a surrogate marker of disruption of the main tumor, was not an indicator of recurrence. It should be noted that there is evidence of lung cancer biopsy dislodging tumor cells into the circulating blood (4).

Recently, inflammation has been suggested to play a key role in lung carcinogenesis (5). Moreover, not only chronic 


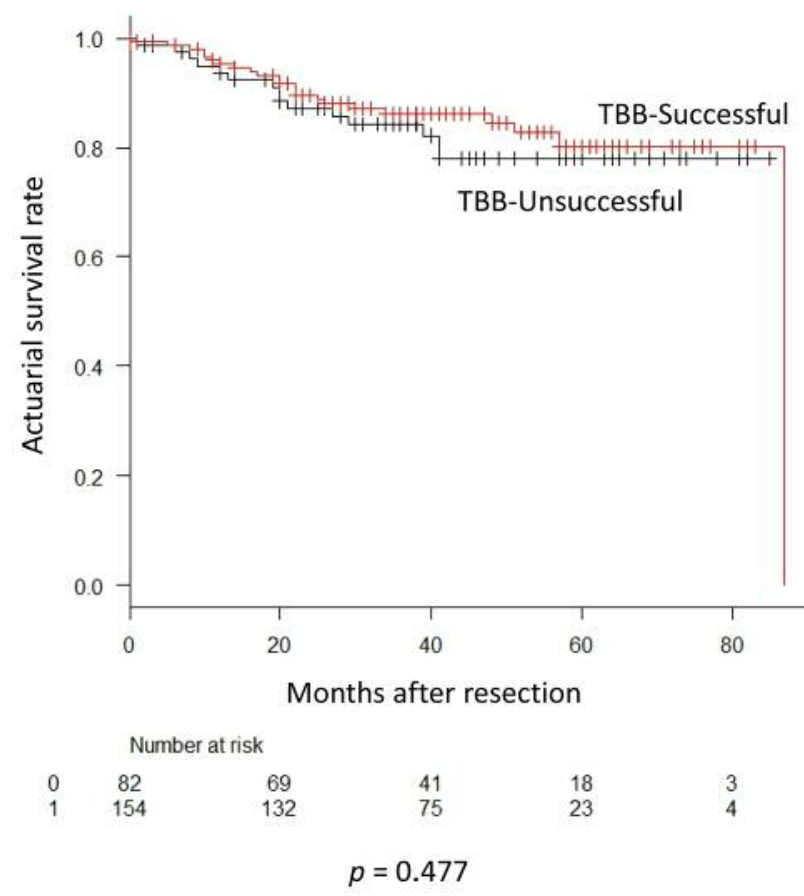

Figure 3. Overall survival curve for all patients according to whether TBB was successful or unsuccessful. The 5-year overall survival rate was $78.0 \%$ in the Successful group and $80.2 \%$ in the Unsuccessful group. The difference between the groups is not significant $(p=0.477)$.

Table IV. Univariate analysis of factors influencing recurrence of all patients after complete resection of primary lung cancer.

\begin{tabular}{lccc}
\hline & Hazard ratio & $95 \%$ CI & $p$-Value \\
\hline $\begin{array}{l}\text { Age }>70 \\
\text { Gender }\end{array}$ & 1.345 & $0.949-1.906$ & 0.095 \\
$\quad$ Male/Female & 1.381 & $0.955-1.998$ & 0.087 \\
BFS & 3.479 & $2.377-5.091$ & $<0.001^{*}$ \\
Period of days from point & & & \\
$\quad$ out to operation $>90$ & 0.464 & $0.322-0.669$ & $<0.001^{*}$ \\
Location & & & \\
$\quad$ Peripherial & 1.013 & $0.679-1.514$ & 0.948 \\
Histology & & & \\
$\quad$ Sq/Non-Sq & 1.414 & $0.925-2.163$ & 0.110 \\
$\quad$ Ad/Non-Ad & 0.603 & $0.420-0.865$ & $0.006^{*}$ \\
Invasive size of the tumor $>3 \mathrm{~cm}$ & 2.744 & $1.937-3.886$ & $<0.001^{*}$ \\
p-N0/N1/N2 or more & 2.871 & $2.364-3.488$ & $<0.001^{*}$ \\
Pl + & 2.673 & $1.883-3.795$ & $<0.001^{*}$ \\
$\quad$ V + & 5.226 & $3.501-7.800$ & $<0.001^{*}$ \\
$\quad$ Ly + & 6.215 & $3.925-9.840$ & $<0.001^{*}$ \\
Preoperative CEA $>5 \mathrm{ng} / \mathrm{ml}$ & 2.284 & $1.613-3.235$ & $<0.001^{*}$ \\
\hline
\end{tabular}

CI: Confidence interval; BFS: fiberoptic bronchoscopy with fluoroscopic imaging; Sq: squamous cell carcinoma; $\mathrm{Ad}$ : adenocarcinoma; Pl: pleural invasion; V: vascular invasion; Ly: lymphatic invasion; CEA: carcinoembryonic antigen.

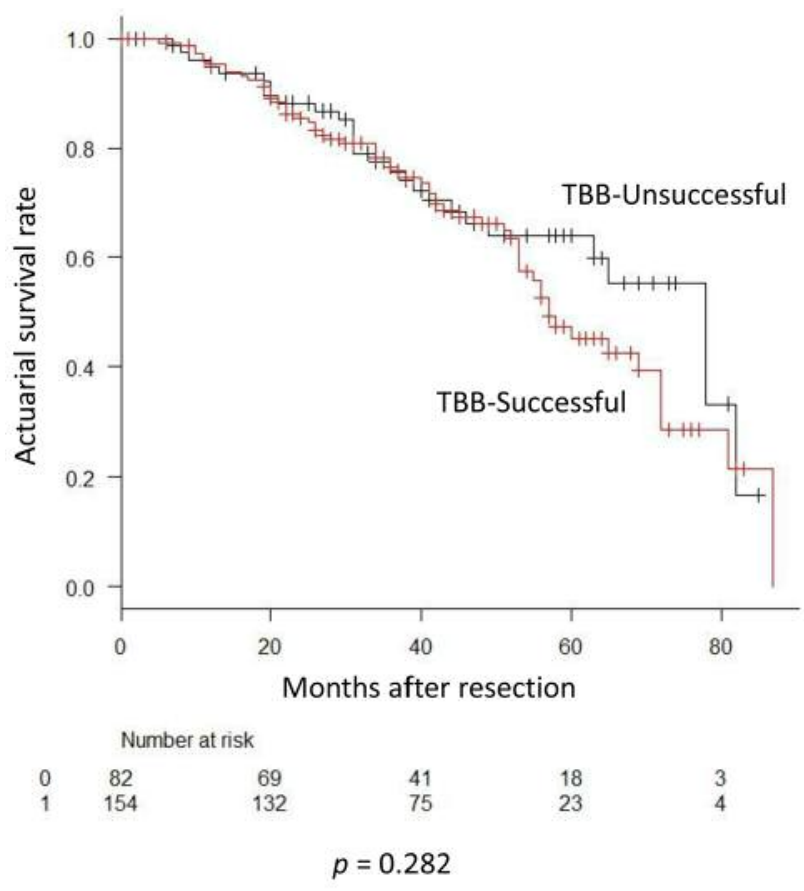

Figure 4. Recurrence-free survival curve for all patients according to whether TBB was successful or unsuccessful. The 5-year recurrencefree survival rate was $63.9 \%$ in the Successful group and $45.2 \%$ in the Unsuccessful group. The difference between the groups is not significant $(p=0.282)$.

Table V. Multivariate analysis of factors influencing recurrence of all patients after complete resection of primary lung cancer.

\begin{tabular}{lccc}
\hline & Hazard ratio & $95 \% \mathrm{CI}$ & $p$-Value \\
\hline $\begin{array}{l}\text { Age }>70 \\
\text { Gender }\end{array}$ & 1.562 & $1.083-2.254$ & $0.017^{*}$ \\
$\quad$ Male/Female & 1.283 & $0.849-1.940$ & 0.237 \\
BFS & 2.164 & $1.399-3.346$ & $<0.001^{*}$ \\
Period of days from point & & & \\
$\quad$ out to operation $>90$ & 0.902 & $0.615-1.323$ & 0.598 \\
$\quad$ Location & & & \\
$\quad$ Peripherial & 1.195 & $0.771-1.851$ & 0.426 \\
Histology & & & \\
$\quad$ Sq/Non-Sq & 0.769 & $0.411-1.437$ & 0.410 \\
$\quad$ Ad/Non-Ad & 0.923 & $0.533-1.599$ & 0.775 \\
Invasive size of the tumor $>3 \mathrm{~cm}$ & 1.209 & $0.800-1.827$ & 0.369 \\
p-N0/N1/N2 or more & 2.398 & $1.857-3.096$ & $<0.001^{*}$ \\
$\quad$ Pl + & 0.890 & $0.593-1.335$ & 0.573 \\
$\quad$ V + & 2.204 & $1.306-3.718$ & $0.003^{*}$ \\
$\quad$ Ly + & 1.387 & $0.756-2.543$ & 0.290 \\
Preoperative CEA $>5 \mathrm{ng} / \mathrm{ml}$ & 1.194 & $0.820-1.739$ & 0.355 \\
\hline
\end{tabular}

CI: Confidence interval; BFS: fiberoptic bronchoscopy with fluoroscopic imaging; Sq: squamous cell carcinoma; Ad: adenocarcinoma; Pl: pleural invasion; V: vascular Invasion; Ly: lymphatic invasion; CEA: carcinoembryonic antigen. 
Table VI. BFS patient's clinico-pathological background.

\begin{tabular}{|c|c|c|c|}
\hline & Successful $(n=154)$ & Unsuccessful $(\mathrm{n}=82)$ & $p$-Value \\
\hline Age $<70 />70$ & $70 / 84$ & $50 / 32$ & $0.029 *$ \\
\hline \multicolumn{4}{|l|}{ Gender } \\
\hline Male/Female & $108 / 46$ & $52 / 30$ & 0.309 \\
\hline \multicolumn{4}{|l|}{ CT findings: } \\
\hline Pure GGN/Others & $6 / 148$ & $5 / 77$ & 0.521 \\
\hline \multicolumn{4}{|l|}{ Location } \\
\hline Peripherial/Others & $107 / 47$ & $66 / 16$ & 0.089 \\
\hline \multicolumn{4}{|l|}{ c-Stage } \\
\hline $\mathrm{Tmin} / \mathrm{T} 1 \mathrm{a} / \mathrm{T} 1 \mathrm{~b} / \mathrm{T} 1 \mathrm{c} / \mathrm{T} 2 \mathrm{a} / \mathrm{T} 2 \mathrm{~b} / \mathrm{T} 3$ or more & $0 / 1 / 17 / 43 / 58 / 21 / 14$ & $0 / 0 / 11 / 38 / 20 / 4 / 9$ & $0.024 *$ \\
\hline \multicolumn{4}{|l|}{ p-Stage } \\
\hline $\mathrm{Tmin} / \mathrm{T} 1 \mathrm{a} / \mathrm{T} 1 \mathrm{~b} / \mathrm{T} 1 \mathrm{c} / \mathrm{T} 2 \mathrm{a} / \mathrm{T} 2 \mathrm{~b} / \mathrm{T} 3$ or more & $0 / 2 / 16 / 32 / 59 / 27 / 18$ & $0 / 4 / 10 / 25 / 23 / 6 / 14$ & 0.052 \\
\hline Invasive size of the tumor $(\mathrm{cm})$ & 3.46 & 3.22 & \\
\hline$<3 />3$ & $66 / 88$ & $49 / 33$ & 0.237 \\
\hline $\mathrm{p}-\mathrm{N} 0 / \mathrm{N} 1 / \mathrm{N} 2$ or more & $110 / 27 / 17$ & $60 / 14 / 8$ & 0.975 \\
\hline \multicolumn{3}{|l|}{ Histology } & 0.098 \\
\hline Ad & 93 & 54 & \\
\hline $\mathrm{Sq}$ & 42 & 13 & \\
\hline Others & 19 & 15 & \\
\hline $\mathrm{Pl}+/-$ & $55 / 99$ & $28 / 54$ & 0.886 \\
\hline $\mathrm{Ly}+/-$ & $94 / 60$ & $54 / 28$ & 0.483 \\
\hline $\mathrm{V}+/-$ & $99 / 55$ & $45 / 37$ & 0.164 \\
\hline \multicolumn{4}{|l|}{ Preoperative CEA } \\
\hline$<5 />5 \mathrm{ng} / \mathrm{ml}$ & $96 / 58$ & $54 / 28$ & 0.671 \\
\hline \multicolumn{4}{|l|}{ Period of days from point out to operation } \\
\hline$<90 />90$ & $101 / 53$ & $46 / 36$ & 0.161 \\
\hline Recurrence & 62 & 28 & 0.400 \\
\hline
\end{tabular}

BFS: Fiberoptic bronchoscopy with fluoroscopic imaging; CT: computed tomography; GGN: ground glass nodule; Ad: adenocarcinoma; Sq: squamous cell carcinoma; Pl: pleural invasion; Ly: lymphatic invasion; V: vascular invasion; CEA: carcinoembryonic antigen.

Table VII. Univariate analysis of factors influencing survival of BFS patients after complete resection of primary lung cancer.

\begin{tabular}{|c|c|c|c|}
\hline & Hazard ratio & $95 \% \mathrm{CI}$ & $p$-Value \\
\hline Age $>70$ & 1.613 & $0.846-3.114$ & 0.154 \\
\hline \multicolumn{4}{|l|}{ Gender } \\
\hline Male/Female & 1.326 & $0.642-2.740$ & 0.446 \\
\hline TBB Success & 0.789 & $0.409-1.521$ & 0.479 \\
\hline $\begin{array}{l}\text { Period of days from point } \\
\text { out to operation }>90\end{array}$ & 0.721 & $0.362-1.435$ & 0.352 \\
\hline \multicolumn{4}{|l|}{ Location } \\
\hline Peripherial & 1.565 & $0.687-3.564$ & 0.286 \\
\hline \multicolumn{4}{|l|}{ Histology } \\
\hline Sq/Non-Sq & 1.485 & $0.734-3.007$ & 0.272 \\
\hline Ad/Non-Ad & 0.612 & $0.321-1.166$ & 0.135 \\
\hline Invasive size of the tumor $>3 \mathrm{~cm}$ & 2.176 & $1.092-4.335$ & $0.027 *$ \\
\hline $\mathrm{p}-\mathrm{N} 0 / \mathrm{N} 1 / \mathrm{N} 2$ or more & 1.807 & $1.205-2.709$ & $0.004 *$ \\
\hline $\mathrm{Pl}+$ & 2.302 & $1.206-4.396$ & $0.012 *$ \\
\hline $\mathrm{V}+$ & 6.119 & $2.165-17.290$ & $<0.001^{*}$ \\
\hline $\mathrm{Ly}+$ & 2.759 & $1.211-6.286$ & $0.016^{*}$ \\
\hline Preoperative CEA $>5 \mathrm{ng} / \mathrm{ml}$ & 2.227 & $1.166-4.254$ & $0.015^{*}$ \\
\hline
\end{tabular}

BFS: Fiberoptic bronchoscopy with fluoroscopic imaging; CI: confidence interval; TBB: transbronchial biopsy; Sq: squamous cell carcinoma; Ad: adenocarcinoma; Pl: pleural invasion; V: vascular invasion; Ly: lymphatic invasion; CEA: carcinoembryonic antigen.
Table VIII. Multivariate analysis of factors influencing survival of BFS patients after complete resection of primary lung cancer.

\begin{tabular}{lccc}
\hline & Hazard ratio & $95 \% \mathrm{CI}$ & $p$-Value \\
\hline $\begin{array}{l}\text { Age }>70 \\
\text { Gender }\end{array}$ & 1.789 & $0.896-2.059$ & 0.635 \\
$\quad$ Male/Female & 1.071 & $0.469-2.446$ & 0.870 \\
$\begin{array}{l}\text { TBB Success } \\
\text { Period of days from point }\end{array}$ & 0.592 & $0.293-1.197$ & 0.144 \\
$\quad$ out to operation $>90$ & 0.827 & $0.400-1.709$ & 0.608 \\
$\quad$ Location & & & \\
$\quad$ Peripherial & 1.944 & $0.812-4.659$ & 0.136 \\
Histology & & & \\
$\quad$ Sq/Non-Sq & 1.067 & $0.384-2.961$ & 0.901 \\
$\quad$ Ad/Non-Ad & 0.794 & $0.306-2.059$ & 0.635 \\
Invasive size of the tumor $>3 \mathrm{~cm}$ & 1.315 & $0.611-2.829$ & 0.484 \\
p-N0/N1/N2 or more & 1.590 & $0.968-2.611$ & 0.067 \\
Pl + & 1.187 & $0.572-2.465$ & 0.646 \\
V + & 5.392 & $1.475-19.720$ & $0.011 *$ \\
Ly + & 0.648 & $0.225-1.862$ & 0.420 \\
Preoperative CEA $>5 \mathrm{ng} / \mathrm{ml}$ & 1.465 & $0.714-3.007$ & 0.298 \\
\hline$\quad$ & & &
\end{tabular}

BFS: Fiberoptic bronchoscopy with fluoroscopic imaging; CI: confidence interval; TBB: transbronchial biopsy; Sq: squamous cell carcinoma; Ad: adenocarcinoma; Pl: pleural invasion; V: vascular invasion; Ly: lymphatic invasion; CEA: carcinoembryonic antigen. 
Table IX. Univariate analysis of factors influencing recurrence of BFS patients after complete resection of primary lung cancer.

\begin{tabular}{lccc}
\hline & Hazard ratio & $95 \% \mathrm{CI}$ & $p$-Value \\
\hline $\begin{array}{l}\text { Age }>70 \\
\text { Gender }\end{array}$ & 1.337 & $0.881-2.031$ & 0.173 \\
$\quad$ Male/Female & 0.939 & $0.607-1.454$ & 0.779 \\
TBB Success & 1.276 & $0.822-2.000$ & 0.287 \\
Period of days from point & & & \\
$\quad$ out to operation $>90$ & 0.701 & $0.447-1.099$ & 0.122 \\
$\quad$ Location & & & \\
$\quad$ Peripherial & 1.237 & $0.761-2.011$ & 0.390 \\
Histology & & & \\
$\quad$ Sq/Non-Sq & 1.338 & $0.822-2.177$ & 0.241 \\
$\quad$ Ad/Non-Ad & 1.042 & $0.676-1.606$ & 0.853 \\
Invasive size of the tumor $>3 \mathrm{~cm}$ & 1.624 & $1.064-2.479$ & $0.025 *$ \\
p-N0/N1/N2 or more & 2.397 & $1.857-3.093$ & $<0.001^{*}$ \\
Pl + & 1.521 & $0.998-2.319$ & 0.051 \\
V + & 2.943 & $1.770-4.893$ & $<0.001^{*}$ \\
Ly + & 2.972 & $1.702-5.190$ & $<0.001 *$ \\
Preoperative CEA $>5 \mathrm{ng} / \mathrm{ml}$ & 2.118 & $1.396-3.213$ & $<0.001^{*}$ \\
\hline
\end{tabular}

BFS: Fiberoptic bronchoscopy with fluoroscopic imaging; CI confidence interval; TBB: transbronchial biopsy; Sq: squamous cell carcinoma; Ad: adenocarcinoma; Pl: pleural invasion; V: vascular invasion; Ly: lymphatic invasion; CEA: carcinoembryonic antigen.
Table X. Multivariate analysis of factors influencing recurrence of BFS patients after complete resection of primary lung cancer.

\begin{tabular}{lccc}
\hline & Hazard ratio & $95 \% \mathrm{CI}$ & $p$-Value \\
\hline $\begin{array}{l}\text { Age }>70 \\
\text { Gender }\end{array}$ & 1.736 & $1.107-2.723$ & $0.016^{*}$ \\
$\quad$ Male/Female & 1.120 & $0.675-1.857$ & 0.661 \\
$\quad$ TBB Success & 1.227 & $0.755-1.996$ & 0.409 \\
Period of days from point & & & \\
$\quad$ out to operation $>90$ & 0.838 & $0.520-1.351$ & 0.469 \\
$\quad$ Location & & & \\
$\quad$ Peripherial & 1.452 & $0.848-2.487$ & 0.174 \\
$\quad$ Histology & & & \\
$\quad$ Sq/Non-Sq & 1.423 & $0.624-3.245$ & 0.402 \\
$\quad$ Ad/Non-Ad & 1.483 & $0.714-3.080$ & 0.291 \\
Invasive size of the tumor $>3 \mathrm{~cm}$ & 1.076 & $0.665-1.741$ & 0.766 \\
p-N0/N1/N2 or more & 2.396 & $1.710-3.356$ & $<0.001 *$ \\
Pl + & 2.990 & $0.515-1.351$ & 0.461 \\
V + & 2.541 & $1.281-5.043$ & $0.008^{*}$ \\
Ly + & 1.085 & $0.514-2.292$ & 0.831 \\
Preoperative CEA $>5 \mathrm{ng} / \mathrm{ml}$ & 1.347 & $0.852-2.129$ & 0.203 \\
\hline
\end{tabular}

BFS: Fiberoptic bronchoscopy with fluoroscopic imaging; CI: confidence interval; TBB: transbronchial biopsy; Sq: squamous cell carcinoma; Ad: adenocarcinoma; Pl: pleural invasion; V: vascular invasion; Ly: lymphatic invasion; CEA: carcinoembryonic antigen. inflammation but also acute inflammation is associated with tumorigenesis (6). Mathenge et al. (7) demonstrated that mice with biopsied breast cancer tumors developed significantly more lung metastases compared to non-biopsied mice. They suggested that the biopsy creates an immunosuppressive tumor microenvironment, while increasing epithelial-to-mesenchymal transition (EMT) and facilitating release of circulating tumor cells (CTCs), all of which likely contribute to the development of distant metastases. Szalayova et al. (11) also reported that diagnostic core needle biopsies in breast cancer patients induced an acute inflammatory response within the tumor microenvironment affecting the surrounding tumor cells. Therefore, biopsy-induced inflammation could have an impact on residual tumor cell progression and/or metastasis in cancer.

Despite not observing significant differences in prognosis and recurrence between the Successful group and the Unsuccessful group, significant differences for prognosis and recurrence were observed between the BFS group and NonBFS group. TBB using BFS could cause dissemination of tumor cells by bluntly tearing or disturbing cells from the main tumor. In addition, TBB is likely to cause inflammation of the lung tissue, regardless of whether it was successful or not. We, therefore, suggest that the BFS procedure alone, and not the TBB procedure, leads to recurrence in postoperative NSCLC patients, due to biopsy-associated metastasis as a result of inflammation.
The limitations of this study include its retrospective design and single institution setting. A prospective study is needed to obtain more accurate evidence.

In conclusion, TBB via BFS was associated with high rate of postoperative cancer recurrence, whereas recurrence was not affected by the success of the TBB procedure. This observation is helpful in improving the diagnostic strategy and outcomes for patients with suspected NSCLC.

\section{Conflicts of Interest}

The Authors declare that they have no conflict of interest regarding this study.

\section{Acknowledgements}

The Authors appreciate the contribution of Drs Chiho Ohbayashi and Tokiko Nakai for the medical records regarding pathological diagnosis.

The Authors thank Dr. Hanne Gadeberg, from Edanz Group (www.edanzediting.com/ac) for editing a draft of this manuscript.

\section{References}

1 Nakajima J, Sato $\mathrm{H}$ and Takamoto S: Does preoperative transbronchial biopsy worsen the postsurgical prognosis of lung cancer? A propensity score-adjusted analysis. Chest 128(5): 3512-3518, 2015. 
2 Sawabata N: Prognosis of lung cancer patients in Japan according to data from the Japanese Joint Committee of Lung Cancer Registry. Respir Investig 52(6): 317-321, 2014.

3 Berger-Richardson D and Swallow CJ: Needle tract seeding after pancutaneous biopsy of sarcoma: Risk/benefit considerrations. Cancer 123(4): 560-567, 2017.

4 Sawabata N, Kitamura T, Nitta T, Taketa Y, Ohno T, Fukumori $\mathrm{T}$, Hyakutake $\mathrm{T}$ and Nakamura $\mathrm{T}$ : Lung cancer biopsy dislodges tumor cells into circulating blood. J Cancer Metastasis Treat 3: 16-20, 2017.

5 Brody JS and Spira A: State of the art. Chronic obstructive pulmonary disease, inflammation, and lung cancer. Proc Am Thorac Soc 3(6): 535-537, 2006.

6 Rosowaki EE and Huttenlocher A: Neutrophilis, wounds, and cancer progression. Dev cell 34(2): 134-136, 2015.

7 Mathenge EG, Dean CA, Clements D, Vaghar-Kashani A, Photopoulos S, Coyle KM, Giacomantonio M, Malueth B, Nunokawa A, Jordan J, Lewis JD, Gujar SA, Marcato P, Lee PWK and Giacomantonio CA: Core needle biopsy of breast cancer tumors increases distant metastases in a mouse model. Neoplasia 16(11): 950-960, 2014.
8 Rami-Porta R, Bolejack V, Crowley K, Ball D, Kim J, Lyons G, Rice T, Suzuki K, Thomas CF Jr, Travis WD and Wu YL; IASLC Staging and Prognostic Factors Committee, Advisory Boards and Participating Institutions: The IASLC Lung Cancer Staging Project: proposals for the revisions of the T descriptors in the forthcoming eighth edition of the TNM Classification for lung cancer. J Thorac Oncol 10(7): 990-1003, 2015.

9 Kanda Y: Investigation of the freely available easy-to-use software 'EZR' for medical statistics. Bone Marrow Transplant 48(3): 452-458, 2013.

10 Nordenstrom B and Bjork VO: Dissemination of cancer cells by needle biopsy of lung. J Thorac Cardiovasc Surg 65(4): 671, 1973.

11 Szalayova G, Ogrodnik A, Spencer B,Wad J, Bunn J, Ambaye A, James T and Rincon M: Human breast cancer biopsies induce eosinophil recruitment and enhance adjacent cancer cell proliferation. Breast Cancer Res Treat 157(3): 461-474, 2016.

Received February 11, 2018

Revised March 18, 2018

Accepted March 19, 2018 